\title{
Expression of CYP2A3 mRNA and its regulation by 3-methylcholanthrene, pyrazole, and $ß$-ionone in rat tissues
}

A.B. Robottom-Ferreira, S.R. Aquino, R. Queiroga, R.M. Albano and L.F. Ribeiro Pinto
Laboratório de Toxicologia e Biologia Molecular, Departamento de Bioquímica, Instituto de Biologia Roberto Alcântara Gomes,

Universidade do Estado do Rio de Janeiro, Rio de Janeiro, RJ, Brasil

\section{Correspondence}

L.F. Ribeiro Pinto

Departamento de Bioquímica

Instituto de Biologia, UERJ

Av. 28 de Setembro, 87 Fundos

$4^{\circ}$ andar

20551-013 Rio de Janeiro, RJ

Brasil

Fax: +55-21-2587-6136

E-mail: fpinto@uerj.br

Research supported by FAPERJ, CNPq and UERJ/SR-2.

Received August 5, 2002 Accepted April 9, 2003

\begin{abstract}
Cytochrome P450 (CYP) 2A enzymes are involved in the metabolism of numerous drugs and hormones and activate different carcinogens. Human CYP2A6, mouse CYP2A5 and rat CYP2A3 are orthologous enzymes that present high similarity in their amino acid sequence and share substrate specificities. However, different from the human and mouse enzyme, CYP2A3 is not expressed in the rat liver. There are limited data about expression of CYP2A3 in extrahepatic tissues and its regulation by typical CYP inducers. Therefore, the objective of the present study was to analyze CYP2A3 mRNA expression in different rat tissues by RT-PCR, and to study the influence of 3-methylcholanthrene, pyrazole and $\beta$-ionone treatment on its expression. Male Wistar rats were divided into four groups of 5 rats each, and were treated ip for 4 days with 3-methylcholanthrene $(25 \mathrm{mg} / \mathrm{kg}$ body weight), pyrazole (150 mg/kg body weight), $\beta$-ionone ( $1 \mathrm{~g} / \mathrm{kg}$ body weight), or vehicle. Total RNA was extracted from tissues and CYP2A3 mRNA levels were analyzed by semiquantitative RT-PCR. CYP2A3 mRNA was constitutively expressed in the esophagus, lung and nasal epithelium, but not along the intestine, liver, or kidney. CYP2A3 mRNA levels were increased in the esophagus by treatment with 3methylcholanthrene and pyrazole (17- and 7-fold, respectively), in lung by pyrazole and $\beta$-ionone (3- and 4-fold, respectively, although not statistically significant), in the distal part of the intestine and kidney by 3-methylcholanthrene and pyrazole, and in the proximal part of the intestine by pyrazole. CYP2A3 mRNA was not induced in nasal epithelium, liver or in the middle part of the intestine. These data show that, in the rat, CYP2A3 is constitutively expressed in several extrahepatic tissues and its regulation occurs through a complex mechanism that is essentially tissue specific.
\end{abstract}

\section{Introduction}

Cytochrome P450 (CYP) enzymes are involved in phase I of xenobiotic biotransformation and in the metabolism of several
Key words

- Cytochrome P450

- CYP2A3

- Esophagus

- Extrahepatic tissue 
Human CYP2A6 is expressed in liver, nasal mucosa (2) and esophagus (3) and is involved in the metabolism of nicotine (4), coumarin (5), and methoxyflurane (6), among others. CYP2A6 is also involved in the metabolic activation of aflatoxin B1 (7), 1,3butadiene (8) and several nitrosamines, including N-nitrosodiethylamine (3). CYP2A6 presents wide individual variability in its expression in different human tissues $(3,9)$. This results in differences between individuals in the metabolism of compounds of pharmacological and toxicological significance. The reasons for the variations in expression are not known, but could be due to different exposure to chemical compounds capable of inducing CYP2A enzymes.

Mouse CYP2A 5 presents $86 \%$ amino acid similarity with CYP2A6 and shares the same substrate specificities (10). The CYP $2 A 5$ gene seems to be regulated in a peculiar fashion because it is not only induced by different unrelated chemicals, such as coumarin, pyrazole, and phenobarbital (11), but, like CYP2A6, is also induced by inflammatory processes such as parasitic infections $(12,13)$.

The rat liver, differently from mice and humans, does not possess significant levels of coumarin 7-hydroxylase, which is associated with CYP2A5 and CYP2A6 (1). This is most likely due to the lack of expression of an orthologous CYP2A enzyme in this tissue (14). The rat, however, possesses an orthologous isoenzyme, CYP2A3, that shows 95\% amino acid similarity with CYP2A5 (15). This enzyme has been shown to be expressed in rat lung (15), nasal epithelium (16), mammary gland (17), and esophagus (14). It is not presently known, however, if it is expressed in other rat extrahepatic tissues. Furthermore, as opposed to mouse CYP2A5, there is no information regarding which compounds are capable of inducing the $C Y P 2 A 3$ gene in different rat tissues.

Therefore, in the present study we determined the expression of the $C Y P 2 A 3$ gene in different rat tissues and the effect of treat- ment with 3-methylcholanthrene, pyrazole, and $\beta$-ionone on its expression.

\section{Material and Methods}

\section{Animals and treatments}

Male Wistar rats $( \pm 200 \mathrm{~g})$ obtained from the FIOCRUZ Central Animal House breeding stock were kept on a 12-h light and dark cycle and were given food and water $a d$ libitum. Each of the four groups of 5 rats was given $1 \mathrm{ml} / \mathrm{kg}$ body weight ${ }^{-1}$ day $^{-1}$ corn oil as vehicle, $25 \mathrm{mg} / \mathrm{kg}$ body weight 3-methylcholanthrene, $150 \mathrm{mg} / \mathrm{kg}$ body weight pyrazole (14), or $1 \mathrm{~g} / \mathrm{kg}$ body weight $\beta$ ionone (18) ip, once a day, for four consecutive days. After treatment, rats were starved overnight and sacrificed by cervical dislocation. The liver, lung, nasal epithelium, esophagus, and intestines were immediately removed and placed in ice-cold sterilized 50 $\mathrm{mM}$ Tris buffer, $\mathrm{pH} 7.4,0.15 \mathrm{M} \mathrm{KCl}$. The esophageal submucosa was removed as previously described (14), and the intestines were divided into three equal parts: the proximal, middle or distal intestine. All tissues were then stored in Trizol (Invitrogen, Carlsbad, CA, USA) at $-20^{\circ} \mathrm{C}$.

\section{RNA extraction and RT-PCR}

Total RNA was extracted from all tissues using Trizol according to manufacturer instructions (Invitrogen). RNA was quantified by spectrophotometry and $500 \mathrm{ng}$ of total RNA from each tissue was used for reverse transcription in a $20 \mu \mathrm{l}$ reaction using Superscript II Reverse Transcriptase (RT; Gibco BRL, Rockville, MD, USA) according to manufacturer instructions.

PCR was performed using $2 \mu$ of the RT reaction mixture and primers for CYP2A3 $(100 \mathrm{ng})$ or for $\beta$-actin $(25 \mathrm{ng})$ as described by Hellmold et al. (17). All PCR conditions were tested to demonstrate that the amplification of $B$-actin and CYP2A3 cDNAs was 
in the linear range (up to 60 cycles of PCR were tested). The primers used in the present study amplified a region of CYP2A3 and Bactin mRNA which spanned an intron in the gene, thus avoiding the amplification of any contaminating genomic DNA. Additionally, in every PCR experiment we performed amplification reactions with RNA that had not been reverse transcribed and also used a DNA-free PCR control. Neither of these controls produced any amplification products (data not shown). Thirty cycles were used for lung and nasal epithelium, 40 cycles for esophagus, whereas 45 cycles were used to amplify kidney and intestine CYP2A3 cDNAs. Twenty-two cycles were used to amplify ß-actin cDNA from all tissues. Additionally, 35 cycles were used for lung, nasal epithelium, and esophagus cDNAs in order to allow a semiquantitative comparison of CYP2A3 mRNA expression between these tissues.

Ten microliters of the PCR mixture from the esophagus, kidney and intestine, $5 \mu \mathrm{l}$ from the lung, or $0.5 \mu 1$ from the nasal epithelium was separated on $6 \%$ polyacrylamide gel and stained with silver (19).

The semiquantitative comparison of CYP2A3 expression between lung, nasal epithelium and esophagus was performed as previously described (3) and normalized in relation to $\beta$-actin expression in these tissues. Data were analyzed statistically by the Student $t$-test using the Instat 2.10 program (Graph Pad Software, San Diego, CA, USA).

The purified amplified DNA product of each tissue was subjected to direct sequencing as previously described (14) in order to confirm the identity of CYP2A3 cDNA.

\section{Results}

We analyzed the expression of CYP2A3 mRNA in different rat tissues. Figure 1 shows that a 398-bp product was obtained from lung, nasal epithelium and esophagus, and a 396-bp product was obtained from liver and distal intestine. We had previously shown that a 398-bp product amplified from nasal epithelium and esophagus corresponds to CYP2A3 cDNA, and that the 396-bp product amplified from liver corresponds to CYP2A1/CYP2A2 (14). Direct sequencing confirmed the identities of the products and showed that the 396-bp product amplified from distal intestine also corresponds to CYP2A1/CYP2A2 (data not shown). There was no amplification of any CYP2A mRNA from the kidney and middle or proximal intestine of untreated rats, even when PCR was carried out for 60 cycles (data not shown).

Figure 2A shows that treatment with 3 methylcholanthrene, pyrazole or $\beta$-ionone

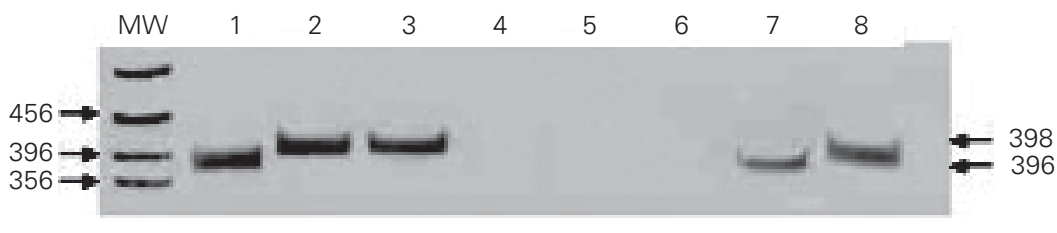

Figure 1. Analysis of constitutive CYP2A3 mRNA expression (398-bp product) by RT-PCR in different rat tissues. Lanes: 1, Liver; 2, lung; 3, esophagus; 4, kidney; 5, proximal intestine; 6, middle intestine; 7, distal intestine; 8 , nasal epithelium. MW, molecular weight standard (pBluescript SK+ digested with Hinfl; Stratagene, La Jolla, CA, USA). The 396-bp product corresponds to CYP2A1/CYP2A2 mRNA.

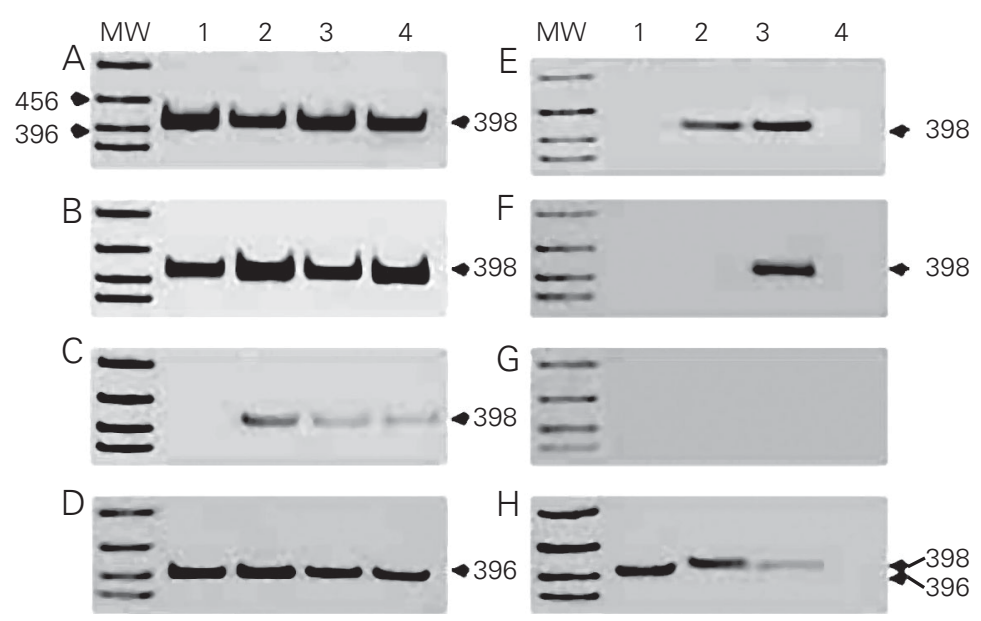

Figure 2. Analysis of CYP2A3 mRNA (398-bp product) expression in different tissues of untreated (lane 1), 3-methylcholanthrene- (lane 2), pyrazole- (lane 3), or ß-ionone-treated (lane 4) rats by RT-PCR. $A$, Nasal epithelium; $B$, lung; $C$, esophagus; $D$, liver; $E$, kidney; $F$, proximal intestine; $G$, middle intestine; $H$, distal intestine. MW, molecular weight standard (pBluescript SK+ digested with Hinfl; Stratagene, La Jolla, CA, USA). The 396-bp product corresponds to CYP2A1/CYP2A2 mRNA. 
did not modify the intensity of the 398-bp product expressed in nasal epithelium. Figure 2B shows that treatment with 3-methylcholanthrene, pyrazole, and $\beta$-ionone increased the intensity of the 398-bp product amplified from lung cDNA. Figure $2 \mathrm{C}$ shows that the three treatments increased the intensity of the CYP2A3 product amplified from esophagus cDNA. In this gel we loaded a smaller amount of cDNA in all lanes to better characterize the induction of the CYP2A3 product. Therefore, the amplified product from the esophagus of untreated rats cannot be seen in this figure. The semiquantitative analysis of CYP2A3 mRNA expression revealed a statistically significant increase in CYP2A3 mRNA levels only in the esophagus with the 3-methylcholanthrene and pyrazole treatments (17.33- and 7-fold, respectively) (Table 1 ).

Figure 2D shows that the liver of untreated rats expresses CYP2A1/2A2 mRNA (a 396-bp product), but none of the treatments used in this study altered its expression level. Figure 2E shows that treatment with 3-methylcholanthrene or pyrazole, but not with $B$-ionone, led to CYP2A3 mRNA expression in rat kidney. Figure $2 \mathrm{~F}$ shows that CYP2A3 is expressed in the proximal intestine after treatment with pyrazole, but not with 3-methylcholanthrene or $\beta$-ionone. Figure $2 \mathrm{G}$ shows that none of the treatments used were capable of promoting CYP2A3 mRNA expression in the middle intestine. Finally, Figure $2 \mathrm{H}$ shows that only CYP2A1/ CYP2A2 is expressed in the distal intestine

Table 1. Induction of CYP2A3 mRNA expression in different tissues of the rat.

\begin{tabular}{lccc}
\hline & 3-MC & Pyrazole & B-lonone \\
\hline Nasal epithelium & 1.74 & 0.74 & 0.76 \\
Lung & 2.09 & 3.00 & 4.27 \\
Esophagus & $17.33^{*}$ & $7.00^{*}$ & 2.66 \\
\hline
\end{tabular}

The rats were treated with $25 \mathrm{mg} / \mathrm{kg}$ 3-methylcholanthrene (3-MC), $150 \mathrm{mg} / \mathrm{kg}$ pyrazole and $1 \mathrm{~g} / \mathrm{kg}$ ß-ionone ip daily for 4 days. Data are reported as "fold" increase compared to respective controls.

${ }^{*} \mathrm{P}<0.05$ compared to respective control (Student $t$-test) of untreated rats, and that treatment with the three drugs decreased its expression. However, treatment with 3-methylcholanthrene or pyrazole promoted CYP2A3 mRNA expression in this tissue.

We carried out a semiquantitative comparison of CYP2A3 mRNA expression in the tissues that constitutively express this enzyme. The expression of CYP2A3 mRNA in nasal epithelium and lung was 819 and 327 times higher than in the esophagus, respectively (data not shown).

\section{Discussion}

The CYP2A subfamily comprises enzymes expressed in different mammals involved in the metabolism of steroid hormones and diverse xenobiotics. They are divided roughly into those that metabolize testosterone, such as rat CYP2A1 and CYP2A2, or mouse CYP2A4, and those that hydroxylate coumarin at position 7 , such as mouse CYP2A5 and human CYP2A6. CYP2A6 and CYP2A5 are orthologous enzymes and have similar substrate specificities and kinetic parameters (1).

Until recently, it was believed that the rat did not possess an orthologous CYP2A enzyme, since rat liver, the major tissue expressing CYP enzymes, does not have significant coumarin 7-hydroxylase activity $(14,20)$. However, Kimura et al. (15) and Ueno and Gonzalez (21) showed that rat lung expresses an enzyme that shares $95 \%$ amino acid similarity with CYP2A5, denominated CYP2A3. In the present study, we showed that CYP2A3 mRNA is constitutively expressed in the rat lung, nasal epithelium, and esophagus, but not in liver, kidney or along the intestine. Our observations of CYP2A3 mRNA expression in these tissues agree with previous studies showing that the CYP2A3 protein is expressed in the nasal epithelium (16) and esophagus (14), and that the mRNA is expressed in the nasal epithelium $(14,22)$ and mammary gland (17). Curi- 
ously, liver and the distal intestine express CYP2A1/2A2, but not CYP2A3 mRNA, whereas nasal epithelium, lung and esophagus express CYP2A3, but not CYP2A1/ CYP2A2 mRNA. This suggests that the regulation of these genes is subjected to compounds that have antagonistic effects, selecting the expression of one or the other enzyme. Although our semiquantitative analysis of expression showed that nasal epithelium and lung present much higher levels of CYP2A3 mRNA than the esophagus, this difference is not necessarily translated into protein levels.

In this study, we showed that the $C Y P 2 A 3$ gene is subjected to a complex regulatory mechanism whereby different classes of chemical compounds are able to induce CYP2A3 transcription in a tissue-dependent manner. Therefore, 3-methylcholanthrene induces CYP2A3 mRNA in lung, esophagus, kidney, and in the distal intestine, but not in liver, nasal epithelium or in the proximal or middle intestine. Kimura et al. (15) had previously shown that 3-methylcholanthrene was capable of producing a 3-fold increase in CYP2A3 mRNA levels in rat lung. 3-Methylcholanthrene, a polycyclic aromatic hydrocarbon, usually induces the enzymes that belong to the CYP1A subfamily in humans and rodents through an increase in gene transcription mediated by the Ah receptor (1). We do not know as yet if the observed increase in CYP2A3 mRNA is mediated by the Ah receptor. As observed in the rat, 3-methylcholanthrene treatment induces CYP2A protein in the hamster lung (23). Unlike the rat, however, CYP2A5 protein and mRNA are not induced by 3-methylcholanthrene treatment in any of the mouse tissues studied (11).

Pyrazole was capable of inducing CYP2A3 mRNA in the esophagus, lung, kidney and in the proximal and distal intes- tine, but not in nasal epithelium, liver, or middle intestine of the rat. Pyrazole is a hepatotoxic drug that induces CYP2E1 protein in the rat liver (24). Pyrazole also induces CYP2A5 protein and mRNA in the liver, but not in the nasal epithelium of mice (16). The mechanism by which pyrazole is capable of inducing CYP2A5 is through mRNA stabilization (25). Although we have shown that pyrazole increases mRNA levels in some rat tissues, we do not know if this occurs through an increase in $C Y P 2 A 3$ gene transcription or through mRNA stabilization.

Finally, $\beta$-ionone was capable of inducing CYP2A3 mRNA in the esophagus and in the lung, but not in the other tissues studied. B-Ionone is a terpenoid compound that, like other terpenes such as B-myrcene, is capable of inducing CYP2B enzymes in rodents $(18,26)$. The mechanism of induction is similar to that of phenobarbital, acting through the CAR receptor (27). Until the present study, however, there were no data regarding the induction of CYP2A enzymes by terpenoid compounds.

Therefore, we have shown that CYP2A3 mRNA is constitutively expressed in rat esophagus, lung and nasal epithelium, but not in the intestine, liver, or kidney. We conclude that $C Y P 2 A 3$ gene expression is subjected to a complex regulatory mechanism in a tissue-dependent manner. Notably, the esophagus responded to all of the treatments tested, whereas the nasal epithelium did not respond to any of them. Curiously, the different parts of the intestine seem to respond differently to the treatments capable of inducing CYP2A3 mRNA in other rat tissues. We are currently analyzing the mechanism by which 3-methylcholanthrene, pyrazole and $\beta$-ionone are capable of inducing CYP2A3 mRNA. 


\section{References}

1. Lewis DFV (1996). Cytochromes P450 Structure, Function and Mechanism. 1st edn. Taylor \& Francis. T.J. Press, London, Bristol, UK.

2. Koskela S, Hakkola J, Hukkanen J, Pelkonen O, Sorri M, Saranen A, Anttila S, Fernandez-Salguero P, Gonzalez F \& Raunio H (1999). Expression of CYP2A genes in human liver and extrahepatic tissues. Biochemical Pharmacology, 57: 1407-1413.

3. Godoy W, Albano RM, Moraes EG et al. (2002). CYP2A6/2A7 and CYP2E1 expression in human oesophageal mucosa: regional and inter-individual variation in expression and relevance to nitrosamine metabolism. Carcinogenesis, 23: 611-616.

4. Nakajima T, Wang RS, Nimura Y, Pin YM, He M, Vainio H, Murayama N, Aoyama T \& Lida F (1996). Expression of cytochrome P450 and glutathione S-transferases in human oesophagus with squamous cell carcinomas. Carcinogenesis, 17: 1477-1481.

5. Miles JS, McLaren AW, Forrester LM, Glancey MJ, Lang MA \& Wolf CR (1990). Identification of the human liver cytochrome P450 responsible for coumarin 7-hydroxylase activity. Biochemical Journal, 267: 365-371.

6. Kharasch ED, Hankins DC \& Thummel KE (1995). Human kidney methoxyflurane and sevolfurane metabolism. Intrarenal fluoride production as a possible mechanism of methoxyflurane nephrotoxicity. Anesthesiology, 82: 689-699.

7. Aoyama T, Yamano S, Guzelian PS, Gelboin HV \& Gonzalez FJ (1990). Five of 12 forms of vaccinia virus-expressed human hepatic cytochrome P450 metabolically activate aflatoxin B1. Proceedings of the National Academy of Sciences, USA, 87: 4790-4793.

8. Duescher RJ \& Elfarra AA (1994). Human liver microsomes are efficient catalysts of 1,3-butadiene oxidation: Evidence for major roles by cytochromes P450 2A6 and 2E1. Archives of Biochemistry and Biophysics, 311: 342-349.

9. Shimada T, Yamazaki H, Mimura M, Inui Y \& Guengerich RP (1994). Interindividual variation in human liver cytochrome P450 enzymes involved in the oxidation of drugs, carcinogens and toxic chemicals: studies with liver microsomes of 30 Japanese and 30 Caucasians. Journal of Pharmacology and Experimental Therapeutics, 270: 414423.

10. Yamano S, Tatsuto J \& Gonzalez FJ (1990). The CYP2A3 gene product catalyzes coumarin 7-hydroxylation in human liver microsomes. Biochemistry, 29: 1322-1329.

11. Pelkonen O, Raunio H, Rautio A, Mäenpää J \& Lang MA (1993). Coumarin 7-hydroxylase: Characteristics and regulation in mouse and man. Journal of the Irish Colleges of Physicians and Surgeons, 22: $24-28$

12. Kirby GM, Pelkonen $P$, Vatanasapt $V$, Camus AM, Wild CP \& Lang MA (1994). Association of liver fluke (Opisthorchis viverrini) infestation with increased expression of cytochrome P450 and carcinogen metabolism in male hamster liver. Molecular Carcinogenesis, 11: 81-89.

13. Satarug $S$, Lang $M A$, Yongvanit $P$, Sithithaworn $P$, Mairiang $E$, Mairiang P, Pelkonen P, Bartsch H \& Haswell-Elkins MR (1996). Induction of cytochrome P450 2A6 expression in humans by the carcinogenic parasite infection, opisthorchiasis viverrini. Cancer Epidemiology, Biomarkers and Prevention, 5: 795-800.
14. Ribeiro Pinto LF, Moraes E, Albano RM, Silva CC, Godoy W, Glosovic T \& Lang MA (2001). The rat oesophageal cytochrome P450 (CYP) monooxygenase system: comparison to the liver and relevance to $\mathrm{N}$-nitrosodiethylamine carcinogenics. Carcinogenesis, 22: 18771883.

15. Kimura S, Kozak CA \& Gonzalez FJ (1989). Identification of a novel P450 expressed in rat lung: cDNA cloning and sequence, chromosome mapping, and induction by 3-methylcholanthrene. Biochemistry, 28: 3798-3803.

16. Bereziat JC, Raffalli F, Schmezer P, Frei E, Geneste O \& Lang MA (1995). Cytochrome P450 2A of nasal epithelium: regulation and role in carcinogen metabolism. Molecular Carcinogenesis, 14: 130-139.

17. Hellmold M, Magnusson M, Pelto-Huikko M, Rylander T, Gustafsson $J$ \& Warner M (1998). Identification of CYP2A3 as a major cytochrome P450 enzyme in the female peripubertal rat breast. Molecular Pharmacology, 53: 475-482.

18. Jeong TC, Gu HK, Park JI, Yun HI, Kim HC, Ha CS \& Roh JK (1999). Pretreatment of male BALB/C mice with ß-ionone potentiates thioacetamide-induced hepatotoxicity. Toxicology Letters, 105: 3946.

19. Sanguinetti CJ, Neto ED \& Simpson AJG (1994). Rapid silver staining and recovery of PCR products separated on polyacrylamide gels. Biotechniques, 17: 915-919.

20. Raunio $H$, Syngelma $T$, Pasanen $M$, Juvonen $R$, Honkakoski $P$, Kairaluoma MA, Sotaneimi E, Lang MA \& Pelkonen O (1988). Immunochemical and catalytical studies on hepatic coumarin 7-hydroxylase in man, rat and mouse. Biochemical Pharmacology, 37: 38893895.

21. Ueno T \& Gonzalez FJ (1990). Complete sequence of the rat CYP2A3 gene specifically transcribed in lung. Nucleic Acids Research, 18: 4623-4624

22. Gopalakrishnan R, Morse MA, Lu J, Weghorst CM, Sabourin CLK, Stoner GD \& Murphy SE (1999). Expression of cytochrome P450 $2 \mathrm{~A} 3$ in rat esophagus: relevance to $\mathrm{N}$-nitrosobenzylmethylamine. Carcinogenesis, 20: 885-891.

23. Pelkonen P, Lang MA \& Pasanen M (1994). Tissue and sex-dependent differences in CYP2A activities in hamsters. Archives of Toxicology, 68: 416-422.

24. Yang CS, Patten CJ, Ishizaki H \& Yoo JSH (1990). Induction, purification and characterization of cytochrome P450 IIE. Methods in Enzymology, 206: 595-601.

25. Geneste O, Raffalli F \& Lang MA (1996). Identification and characterization of a $44 \mathrm{kDa}$ protein that binds specifically to the 3 '-untranslated region of CYP2a5 mRNA: Inducibility, subcellular distribution and possible role in mRNA stabilization. Biochemical Journal, 313: 1029-1037.

26. De-Oliveira ACAX, Ribeiro Pinto LF, Otto SS, Gonçalves A \& Paumgartten FJR (1997). Induction of liver monooxygenases by $\beta$ myrcene. Toxicology, 134: 135-140.

27. Sueyoshi T \& Negishi M (2001). Phenobarbital response of cytochrome P450 genes and nuclear receptors. Annual Review of Pharmacology and Toxicology, 41: 123-143. 